\title{
Competitive advantage through participation in standards setting?
}

Link to publication record in Manchester Research Explorer

\section{Citation for published version (APA):}

Jakobs, K., Procter, R., \& Williams, R. (1997). Competitive advantage through participation in standards setting? In Anon (Ed.), IEE Conference Publication/IEE Conf Publ (pp. 370-375). IEE.

\section{Published in:}

IEE Conference Publication|IEE Conf Publ

\section{Citing this paper}

Please note that where the full-text provided on Manchester Research Explorer is the Author Accepted Manuscript or Proof version this may differ from the final Published version. If citing, it is advised that you check and use the publisher's definitive version.

\section{General rights}

Copyright and moral rights for the publications made accessible in the Research Explorer are retained by the authors and/or other copyright owners and it is a condition of accessing publications that users recognise and abide by the legal requirements associated with these rights.

\section{Takedown policy}

If you believe that this document breaches copyright please refer to the University of Manchester's Takedown Procedures [http://man.ac.uk/04Y6Bo] or contact uml.scholarlycommunications@manchester.ac.uk providing relevant details, so we can investigate your claim.

\section{OPEN ACCESS}




\title{
COMPETITIVE ADVANTAGE THROUGH PARTICIPATION IN STANDARDS SETTING?
}

\author{
Kai Jakobs ${ }^{1}$, Rob Procter, Robin Williams
}

The University of Edinburgh, UK

The paper discusses the question whether or not large corporations should actively champion their needs and requirements in the international standards setting process. Taking the electronic mail service as an example, views of company representatives and senior members of relevant standards committees are reported. These statements have been compiled through interviews and questionnaires. To a considerable extent both parties agree that increased user participation cuts both ways. Based on these opinions, some proposals are made how to provide convenient means for input from the user side whilst avoiding the perceived drawbacks of direct committee participation.

\section{INTRODUCTION AND MOTIVATION}

For quite some time Information Technology (IT) has been at the very heart of every large organisation. More recently, electronic data communication services started playing an extremely crucial role, practically forming the lifeline of these organisations. This holds particularly for the electronic mail (e-mail) service, which provides a fast, efficient and function-rich alternative to both, letter and telephone.

Over the last ten or so years three crucial trends resulted in the need for global, non-ambiguous and adequate standards for communication services for the business community. These trends reflect the general development of increased globalisation of and collaboration between businesses:

\section{- integration}

companies are merging or acquired, with a very high likelihood of resulting heterogeneous IT and communication environments,

\section{- internationalisation}

moving into new markets will require adaption to the respective dominant local system (as eg. X.400 in Europe and the Internet in the US),

\section{- cooperation}

the degree of cooperation even between possible competitors is increasing, again yielding the need for reliably working inter-company communication services.
One of the major developments in the IT sector reflecting these trends was the move from proprietary email systems - almost exclusively employed until the early eighties - towards 'open' systems - ie. TCP/IP or OSI-based communication networks in general and email services in particular. However, this represented only the first step towards globally homogeneous, useful and usable communication services. Today, major issues include interoperability between these two communication worlds, full implementation of the respective standards, and integration of high-level communication services into existing IT-infrastructures.

On the other hand, international standardisation bodies such as ISO and ITU have been struggling to keep in touch with the fast developments primarily triggered by the market. New procedures (eg ISO's Fast Track) have been adopted, and even new bodies have been funded (such as the European Telecommunications Standards Institute) in an attempt to deliver adequate standards specifications in a timely fashion.

This paper will discuss the need for standards in the field of e-mail, which has made its way into the offices of virtually all major international organisations. and will review the pros and cons of the participation of user company representatives in the standardisation process. The discussion will largely be based on interviews done with representatives from both, large, globally operating corporations and standardisation committees.

\section{USERS IN IT-STANDARDISATION}

Given the very diverse nature of the groups involved in the standards setting process it is easily conceivable that their opinions differ widely with regard to user participation. A reasonably uneducated initial guess would be that the 'official' point of view calls for stronger participation of user representatives. In an increasingly competitive standardisation environment the idea would be that user participation can help raise specifications' chances of survival in the market place. It is - or at least one would want to think it is - in every standards setting organisation's interest to produce specifications that meet the demands and requirements of their prospective users, and thus stand a chance to be actually employed as a basis for products or services. 
On the other hand, work group members will hardly be pleased by the idea of an increasing number of participants. To make matters worse, these new members may be expected to be not as technically sophisticated as standardisation 'professionals' would deem necessary. Accordingly, you could anticipate major reservations against a larger number of user representative on the committees. Yet, assuming that single committee members also like to see the specifications they are producing being turned into products, one might also expect that user participation is considered useful if restricted to requirements collection and reviewing, as opposed to fiddling about with the purely technical aspects.

Looking at the issue from yet another angle, you could expect users themselves to be quite ambivalent in their views. Leading edge users, strategically employing state-of-the-art technology to support advanced applications and organisational structures are likely to have clear additional requirements on existing services. They may therefore decide to carry these requirements into the standards setting process. To have at least a realistic chance of success, however, their efforts should be backed by sufficient spending power. That is to say, if leading edge users at the same time happen to be sufficiently large (ie Boeing, General Motors, British Airways, Reuters and the like) they may well be in a position of being successful with pushing their requirements through.

In contrast to that, you would expect that less sophisticated organisations without far-reaching requirements will tend to consider involvement in standardisation being just not worth the effort. They will either try to get by on what they have got, to talk to their service providers and/or vendors in order to get 'customised' solutions (with all the risks and problems associated with this approach), or to solve the problems internally by integrating 'home-made' enhancements (with largely the same problems as customised solutions). Moreover, to actively get involved in the standards setting process will probably be regarded as being far too expensive and time consuming for smaller users ('Small and Medium Enterprises - SMEs, to use the popular EU-term), especially in times of recession. What's more, the eventual outcome of such involvement lies too far in the future, and is far too uncertain, as to be of any perceived real benefit.

\section{The Users' Side}

One general finding so far has been that corporations, even larger ones with a very favourable general attitude towards e-mail, show very little interest to influence standards setting. This holds despite an (although limited) number of identified functional shortcomings. Instead, we found that they look to service providers and vendors to come up with solutions to such problems. Apparently, companies do not see any business benefits in standards activities and are therefore not prepared to spend considerable amounts of money on people travelling to meetings and working on standards committees. Where representatives of corporate users do participate in standardisation, this appears to be largely based on "personal initiative plus a supportive director" [Jakobs et al., 1996].

There are a number of factors which might explain this result. One is the current corporate perception of e-mail. Of the large number of mail-enabled applications available, only a handful were represented amongst the corporate users in our study; interpersonal messaging was unanimously identified as the single most important e-mail application. Thus, within our sample, e-mail at present is little more than a very convenient new communications medium. In particular, in the vast majority of our case studies it is not as yet employed as part of any business-critical processes, and so far has no real strategic significance. Indeed, interviewees reported that sending business-related information via e-mail is discouraged in almost all the European companies in the study. This is largely - though not exclusively - due to the perceived lack of security of the medium (see also eg [Jakobs and Lenssen, 1994]). US companies apparently adopt a more relaxed attitude.

Another important factor underlying current attitudes towards participation in standardisation is the way in which corporate e-mail services have developed [Fichtner et al., 1996]:

- For quite some time other, more down-to-earth email related issues had to have higher priorities (like eg. providing reasonably smooth interworking between different systems).

- Strategic planning in this area has started only fairly recently, in particular, e-mail has not yet been part of strategic applications. Therefore, little, if any, additional functionality has been needed so far.

- Problems identified stem largely from inadequate implementations of the standards rather than flawed standards. As one consequence, the direct links are to system vendors and service providers rather than to the standardisation bodies.

This is seconded by two notions: first, a requirements analysis, the outcome of which would be the basis for any meaningful participation in standards bodies has not normally been performed. Second, apparently US organisations are more active in standardisation bodies. Given that the US are a couple of years ahead of Europe in terms of corporate e-mail usage, especially as far as 
business-critical use is concerned, you may expect to observe a similar development in Europe in about three to five years time [Jakobs et al., 1997]. This is, however, just a spotlight, more data will be needed to substantiate this prediction.

One further factor may contribute to the reluctance to participate in standards setting: the vast majority of functional shortcomings, flaws and problems identified by interviewees stemmed from poor implementations of standards, rather than inadequate standards per se.

The shortcomings and problems cited most often include addressing, notifications (an indication that a message has been delivered to, or received by, the addressee), security, transmission of binary files, and more comfortable editing facilities. From these, the only one truly related to a deficiency in a standard is addressing in X.400. Apart from that, the others merely emphasise that current implementations of messaging standards are less than satisfactory. This holds for X.400, and to some lesser extent for the Internet as well.

X.400 provides for a number of different notifications, including 'delivery notifications' and 'receipt notification request indications'. Many security features have been specified as well, designed to cope with (amongst others) problems of masquerading, modification of information, repudiation and leakage of information. Again, the problem is that these are rarely implemented. Transmission of binary files represents a major problem to some Internet users for similar reasons.

In the light of the above it seems understandable that a corporate user would rather persuade a vendor to offer a full implementation of a standard in the first place, than go to great lengths and push additional functionality into a standard specification. This holds all the more since none of the interviewees reported pressure from end-users for functionality beyond what is currently being provided (typically apart from local implementation details), and none of the service providers has yet been confronted with user requirements beyond X.400's functionality.

\section{The Standardisation's Side}

Standardisation is not a simple technical activity but is influenced by political, economic and social factors (cf eg [Hawkins 1995]). With the search for standards that are truly global and increasingly comprehensive, standards setting must cater for an ever increasing range of players. Thus, it is little wonder that the formal processes of ISO and ITU tend to be frustratingly slow, and apparently, sometimes highly ineffective.
Figure 1 shows the picture of the relations between players in standards setting process (at Work Group level, where the actual technical decisions are being made) which emerged from our study [Jakobs 1996a].

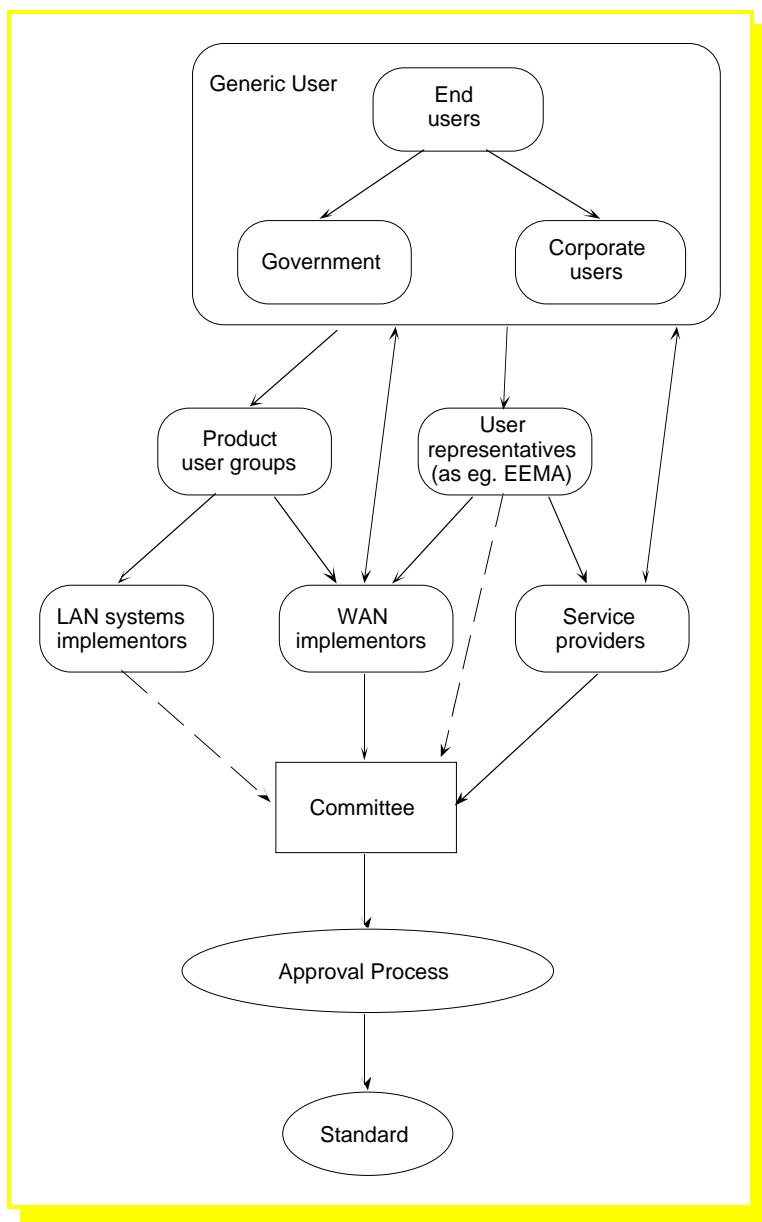

Figure 1: Relations Between Stakeholders in the Standardisation Process

It could be concluded that implementors and service providers - deliberately or not - act as a 'buffer' between users and standards committees (the double-arrows in the figure). Helping their customers (the users) to resolve short-term problems in an ad-hoc manner implies that established processes and procedures are being bypassed for the sake of a quick solution. As a result, you might suspect that at least some user requirements simply do not make it into the standardisation process because of this 'buffering' phenomenon. Moreover, there is a danger of creating incompatibilities if additional service elements are added only to meet single user demands.

Although standardisation bodies have attempted to promote greater user participation in standards setting (cf eg [ETSI 1992] or [ISO 1995]), our study indicates that this has not been a success. Standards setting within communications services, even for the higher, more user-oriented layers, continues to be largely technology driven and supplier or vendor led. As such, the services offered tend to reflect suppliers' and/or vendors' 
priorities (eg manageability) rather than user needs, eg usability. It would seem that the influence of communication service users is limited to the marketplace, where their choices may already be limited.

\section{The Committee Members' Side}

Amongst standards committee members opinions are somewhat split on whether or not increased user participation would be of benefit. Whilst there is no general disagreement that input on real user requirements could lead to a wider and/or faster acceptance of standards-based products in the marketplace, there is also considerable reluctance to increase the size of committees even further. Moreover, users are widely considered as being not sufficiently knowledgeable in technical terms, and thus be more a millstone around the neck than anything else. This position is understandable if user participation is pursued within current standards setting procedures and frameworks; an already cumbersome and often ineffective process would become even more so.

However, there have also been outspoken supporters of more user input to the committee work. In fact, and maybe somewhat surprisingly, these supporters form the majority:

\begin{abstract}
"We don't think our standards would have come into being without user involvement. The vendors wouldn't have done it for us. What we need now is a method to make the users even better participants, without asking them to travel all over the world." (committee member, 1995).
\end{abstract}

Still, a significant degree of reluctance to let user representatives have a greater say in the process is apparent as well:

"I am sorry to say the contrary of what is generally expected but I do not believe in the interest of users' opinion, at least in Telecommunications. Users need to transmit the maximum of data to the best price. After that, they do not care if it is IP, X.25 or Frame Relay. Or if they care, it is because it is writen in their newspaper that this technique is the best one!

Telecommunication domain is very complex. And most of users have not the time (and it is not their job) to analyse technical things in that matter. I believe that users' needs are best defined by operators people, in the condition that there was a good link, internally to the operator's company, with the client (genreally through sales people)." (committee member, 1996)
Finally, a third group was in support of increased user participation under certain conditions, or within only limited areas where these respondents felt users could contribute:

\begin{abstract}
"Possibly for the generation of requirements, user participation might be useful. But, I think not for solutions, because, in general, the users do not 'engineer' the solutions." (committee member, 1996)
\end{abstract}

These quotes pretty accurately reflect (in decreasing order) the three predominant schools of thinking popular among senior committee members.

\section{Considering User Requirements}

The integration of user requirements into the standards' specification process is of potentially crucial importance for users. If their requirements were adequately identified and dealt with, there would be no need to participate. The formal procedures which have been established by the 'official' standards setting bodies leave you with the impression that well-defined user requirements are essential and an important part of the process. Indeed, it seems that without adequate requirements from the user side no activities at all are initiated. However, the question remains whether these procedures are actually adhered to, and how the reality in the work groups and committees looks like with respect to 'integrating user requirements'. The answer to this question should to a considerable degree influence stance users' take up at participation in the standards setting process.

A straightforward approach would be to consult - better yet to invite - user groups or associations, representatives of which could actively participate in the standardisation process and could act on behalf their respective constituency. This should be done either before the actual standardisation activity commences, or during its very early stages. In theory representatives form users and user associations are free to participate in the process. In practice, users are dramatically underrepresented in the committees.

Both formal and informal cooperations have been acknowledged by the respondents. Formal cooperation is in place in a few work groups, whilst others reported no such links. Typically, formal cooperation is on a liaison basis, that is, the user group participates in meetings and receives the written output, but has no right to vote. There are also informal cooperation through personal contacts, or through organisational delegates wearing the additional hat of a user group representative.

\footnotetext{
"Relevant user groups are granted liaison status with committees; in some cases the liaison is 'formal', meaning that paper is
} 
transferred, in other cases a representative of the user group attends meetings regularly." (committee member, 1994).

Yet, it seems that all cooperations are at the discretion of the respective committee, and that it is very much by chance if cooperation in whatever form occurs.

Another approach, adopted and subsequently canceled by both, ISO JTC1/SC18 and ITU-T, was to employ a 'user requirements' WG (the term 'service definition group' was used by ITU).

"SC18 made a big show of developing user
requirements; it even had a whole working
group devoted to the process. I think the
effort largely failed because (1) nobody could
agree on what a user was, (2) the other WGs
tended to look at WG1 (the user requirements
group) as an impediment, and (3) when
budgets got tight, nobody could afford to
send real users to meetings just to oversee a
process." (committee member, 1994).

However, it looks very much as if this approach was a failure in the eyes of many committee members - if they happen to know about such groups in the first place. Whilst overall the comments range from "invaluable to the standardisation process" to "at best as not necessary and at worse a hindrance.", most of the interviewees, including ITU members, conceded that they had no idea what this group did, or that they did not have sufficient experience (if any) with their work to comment on it.

A popular perception held by a number of respondents can be summarised as follows:

"Unlikely to be valid representatives and
often negatively regarded by those who
believe they do the 'real work'." (committee
member, 1995).

This seems to be a major issue here. Even if a 'user requirements' group were established, they would have a major credibility problem with two different facets: First, the group would need to prove that it actually is a representative of the whole user community, and not just representing, for instance, some very large users or users of specific products only. Second, it would be an uphill struggle to convince members of the technical groups that they do valuable work and contribute significantly to the overall process. Especially the latter, rather more psychological problem is almost impossible to overcome in the short term (if at all).

\section{FINAL REMARKS AND CONCLUSIONS}

The 'official' standardisation processes (i.e. those embraced by ISO and ITU and, to some degree, by the IETF), are widely perceived as being costly and time consuming. Moreover, once a problem has been identified by a user it will definitely be too late to try and solve it through establishing a new, or modifying an existing standard (a process which typically takes years). Thus, it does not exactly come as a surprise that companies are very reluctant to invest in people (employees or consultants) to champion their needs in standards committees, without any guarantee of success.

Given the process as it currently stands, users cannot be blamed for their reluctance. Ad-hoc problems can far easier be solved through contacting the implementor or service provider, and to address long-term, strategic problems that way is an extremely costly and risky business.

There are two more issues to be considered. Firstly, from the responses of corporate representatives in can be concluded that during the early stages of the employment of a new (interpersonal) communication system users typically do not have any real functional requirements. Even today e-mail hasn't quite gained real strategic significance in most companies, and remains little more than a convenient interpersonal communication tool, complementing and maybe gradually replacing phone and fax machines.

Secondly, it appears that new ways of incorporating user input into standards setting processes are required. The process is lengthy and costly, with no short-term return on investment from participation in sight for users. Moreover, when it comes to technical problems users apparently would have a credibility problem in quite a few committees, as have dedicated user requirements groups. Standards organisations should look urgently at how to utilise new electronic media for discussion, information dissemination and, last not least, to facilitate greater user participation in standards setting, at least for requirements compilation. However, it should be noted that a considerable number of standards committee members second this proposal. In fact, (better) use of readily available electronic communication media could generally improve and speed up the process.

Another alternative to foster increased user participation while at the same time taking into account the concerns voiced by committee practitioners could be the channeling of user input through established international and independent dedicated user organisations. Such organisations would be in the position to represent all their members in the standardisation process. In fact, the World Electronic 
Messaging Associations (WEMA), for example, are considering to become active in this area. However, it should be noted that this is not a first, the International Telecommunications User Group (INTUG) has long been representing users especially in committees of the ITU (although apparently not too successfully).

Whereas benefits of standards and standardised e-mail services have been acknowledged and appreciated by all users in our study, identified user requirements in terms of additional functionality are few. This situation, however, is likely to change: with the ongoing diffusion of electronic messaging services into companies and organisations, and especially with the predictable integration of e-mail into business-critical processes, additional needs are likely to emerge, which cannot be fulfilled by simply talking to vendors or service providers. We would therefore predict increasing user involvement in the standardisation process in the nottoo-far future.

Finally, to summarise the answer to the question raised in the title: under current circumstances users should expect to gain little benefits from participation in standards setting. With upcoming new requirements, and with new procedures designed to simplify participation in the process, this will change in the medium term.

\section{REFERENCES}

ETSI 1992, Progress on User Participation in the Standardization Process, presented at the $\underline{3 r d}$ Interregional Telecommunications Standards Conference, Tokyo 1992

Fichtner, M.; Jakobs, K.; Procter, R.; Williams, R., 1996, Corporate E-Mail in Europe - Requirements, Usage and Ways Ahead; Proc. 4th Int. Conf. on Telecommunication Systems, Modelling and Analysis. Hawkins, R.W. et al. (eds),1995, Standards, Innovation and Competitiveness, Edward Elgar Publishers.

International Organization for Standardization (eds), 1995, Raising Standards for the World - ISO's longrange strategies 1996-1998.

Jakobs, K.; Lenssen, K., 1994, Successful Applications of Electronic Messaging in International Organizations Strategies, Results, Experiences, Report of the European Electronic Messaging Association.

Jakobs, K.; Procter, R.; Williams, R., 1996, A Study of User Participation in Standards Setting;CHI '96 Conference Companion, ACM Press.

Jakobs, K.; Procter, R.; Williams, R., 1997, Introducing IT: Lessons From Case Studies of E-Mail, This volume.

1 Author's present address:

Kai Jakobs, Technical University of Aachen, Computer Science Department, Informatik IV, Ahornstr. 55, D-52056 Aachen, Germany, jakobs@informatik.rwth-aachen.de 